e-ISSN: $1984-4255$ ARGUMENTOS

D0I: https://doi.org/10.36517/Argumentos.23.4

\title{
A crise da razão: elementos para pensar a educação moral no campo da Bioética
}

\author{
The crisis of reason: elements to think about moral \\ education in the field of Bioethics
}

\author{
João Cardoso de Castro \\ http://orcid.org/0000-0002-3811-405X - E-mail: joaocardosodecastro@gmail.com \\ Murilo Cardoso de Castro \\ http://orcid.org/0000-0001-8809-5443 - E-mail: murilocdecastro@gmail.com
}

\begin{abstract}
RESUMO
É lugar comum a ideia de que vivemos uma crise moral, que nos assola de maneira radical nos dias de hoje. Neste sentido, um fluxo grande de trabalhos, no campo da Saúde, procura delinear os contornos específicos desta crise, bem como esboçar algumas possibilidades de enfrentamento aos seus desdobramentos, com ênfase no que se consagrou na literatura como "educação moral". Na esteira destas questões, propomos este artigo cujo objetivo é estabelecer uma perspectiva diferente para a crise. Através de um esforço de natureza filosófica, e tendo o filósofo Martin Heidegger como guia desta caminhada, procuramos discutir a referida crise, abordando sua natureza mais essencial e denunciando a insuficiência da "educação moral" contemporânea face à natureza da crise.
\end{abstract}

Palavras-chave: Crise. Modernidade. Razão. Educação moral. Heidegger

\begin{abstract}
It is a commonplace the idea that we are facing a moral crisis, which rages us in a radical way these days. In this sense, a great flow of work in the field of Health seeks to delineate the specific contours of this crisis and outline some possibilities to confront with its unfolding, with emphasis on what has been consecrated in the literature as "moral education". On the track of these questions, we propose this article that aims to establish a different perspective for the crisis. Through an effort of philosophical nature, and with the philosopher Martin Heidegger as a guide in this journey, we sought to discuss the crisis by addressing it's most
\end{abstract}


essential nature and denouncing the insufficiency of contemporary "moral education" in face of the nature of the crisis.

Keywords: Crisis. Modernity. Reason. Moral education. Heidegger.

\section{Introdução}

Acreditamos que não seja exagero dizer que é imanente à natureza humana julgar, consciente ou inconscientemente, pessoas a nossa volta, seus hábitos e comportamentos. O mundo sempre nos provocou. Sentimo-nos convidados a explicar o que nos cerca. Tudo pode ser colonizado pela explicação e faz parte do homem esta dimensão "hermeneuta". Conta-se que Heidegger perguntava a seus estudantes: "qual é a primeira coisa que encontramos em nossa vida? Coisas, objetos, seres? Não!, dizia o alemão: é sentido ("significância"; Bedeutung, em alemão). Damos sentido, "valoramos" as coisas. Mais tarde, em suas obras, Heidegger dará o nome de "acontecimento apropriador" (Ereignis) à esta abertura, à essa clareira de sentido que é o homem. Orientados desde sempre no horizonte de interpretação do ente da cultura judaico-cristã, "colorimos" os acontecimentos desde uma clivagem: o bom e o mal. Assim, muita tinta se verteu sobre os conceitos de certo e errado, refletindo sobre como deveríamos viver, o que é a "vida boa" e quais os comportamentos e virtudes ideais e, neste sentido, toda reflexão que pretende identificar a melhor forma de viver e conviver se articula, necessariamente, com o que se consagrou como "moral" e, de um modo geral, se existe uma disciplina filosófica que poderíamos chamá-la de prática, esta seria, sem dúvida, a Ética.

É lugar comum a ideia de que vivemos hoje uma "crise" moral, e é bem provável que estejamos, enfim, na radicalidade da crise (CABRAL, p. 18). De uma "crise como jamais houve sobre a Terra, da mais profunda colisão de consciências", conforme prenunciou Nietzsche, magistralmente, em seu Ecce Homo (2004, p. 117). Abundam trabalhos e perspectivas que procuram delinear a dita "crise", diagnosticar os motivos que nos conduziram à ela e, na esteira de um iluminismo pueril, acadêmicos e intelectuais se apressam a prescrever elaborados sistemas de normas e regras. O resultado não poderia ser outro: um enorme fluxo de trabalhos espraia-se no horizonte da reflexão moral sendo apropriados por todos os campos da atividade humana. A perda de valores absolutos e universais que, de alguma forma, vem à tona no período moderno, com o surgimento de sociedades complexas, com uma pluralidade de crenças, valores e comportamentos, é bastante conhecida. A irrefreável produção de bens materiais e simbólicos amarrados a uma visão "liberal" é capaz de fazer "brotar" em nós uma ambição quase capilar por toda a parafernália produzida. Assim, a existência humana não passaria, então, de um "meio" pelo qual o "sistema" se alimenta e reproduz sua lógica perversa. Como bem diz o filósofo Giorgio Agamben (s/d): “Deus não morreu. Ele tornou-se Dinheiro [...] O capitalismo é uma religião, [...] um culto ininterrupto cuja liturgia é o trabalho e cujo objeto é o dinheiro."

No bojo deste arranjo perigoso, pesquisadores e intelectuais entendem que os próprios "conflitos" de natureza ética parecem se intensificar nos dias de hoje. No campo das ciências da saúde, nosso horizonte específico de reflexão, alguns discursos enxergam a tal "crise" a partir do desenvolvimento das biotecnociências. Estas vozes, que ressonam sobretudo no campo da Bioética, se esforçam para nos convencer de que desde o advento das "novas tecnologias" - e toda gama de problemas que se produziu no interior desta apropriação - faz-se necessário catalisar esforços em torno de uma mudança paradigmática do que se entende por "ética" na saúde. Estudos como o de Zoboli e Fortes (2004), Siqueira-Batista (2005) entre outros (REGO; COSTA-MACEDO, 2005; VIDAL, 2014; MOTTA, 2012), evidenciam a ideia, já lugar comum, de que 
os códigos de ética profissional não dão conta da multiplicidade de conflitos que emergem no cotidiano dos profissionais de saúde e, neste sentido, a construção de um arcabouço teórico que permita a identificação dos problemas éticos e sustente suas tomadas de decisão se torna premente. Neste sentido, existe uma certa consonância de que grande parte da solução para esta dificuldade estaria na própria "formação" destes profissionais de saúde e, neste sentido, buscam-se subsídios para uma "educação moral", sobretudo, a partir da identificação das práticas pedagógicas mais eficientes para a fundação de alicerces éticos, nestes indivíduos, que possam contribuir no enfrentamento dos seus conflitos. Estudos como o de Mitre e outros entendem que uma orientação moral baseada nos princípios bioéticos, onde os profissionais de saúde possam construir o próprio conhecimento (MITRE et al., 2008), no sentido de aguçar a capacidade de identificação dos problemas éticos que vivenciam e, pode ajudar muito na "tomada de decisão". Neste cenário, a Bioética entendida como uma prática de segunda ordem, ou seja, cujos reflexos e resultados poderiam ser sentidos nos atos e fatos que estas equipes participam, vem ganhando força na área da saúde.

Não caberia, dentro dos limites de um artigo, elencar o infindável arcabouço teórico produzido na academia acerca de diagnósticos e soluções sobre e para a "crise", mas é fato que, diante da "crise" - ou do aprofundamento da "crise" - é lugar comum a ideia de que a "educação moral" é o caminho mais eficaz de enfrentamento à questão. Embora não discordemos deste entendimento, acreditamos que, de um modo geral, tanto diagnóstico como propostas de educação moral na área da saúde se assentam sobre interpretações equivocadas do que significa "homem", o "ser" do homem ou, ainda melhor, o "ser"-humano. E na esteira dessa interpretação mutilada de "homem", vimos grande parte da reflexão ética moderna - e, por conseguinte, do que se consagrou como "educação moral" - abordar a ética de maneira tão estreita que seus desdobramentos se resumem a discutir nuances da pergunta: "o que é certo fazer?". Assim, questões essenciais à ética, como "o que é bom ser?" ou ainda, "o que é ser?", são soterradas por camadas e mais camadas de doutrinas ou "catecismos que venham a orientar o agir humano." (CABRAL, 2009, p. 24).

Colocadas estas noções preliminares, o objetivo deste trabalho é discutir a referida crise, abordando sua natureza mais essencial e denunciar a insuficiência da "educação moral" contemporânea face à natureza da crise. Nos servirá de guia nesta empreitada o pensamento do filósofo alemão Martin Heidegger, em sua leitura e apropriação do pensamento grego. Cabe esclarecer também, ainda nesta introdução, que embora não compartilhemos com as abordagens e ideias de grande parte do que é produzido em termos de diagnóstico e proposições para a "crise" mencionada, existe de fato uma espécie de afinação quando se trata de perceber que há algo aí "digno de ser pensado", como nos diz Heidegger (1996, p. 80). Isto posto, nosso objetivo se divide em dois momentos distintos, embora complementares, a saber: (1) delinear, ainda que de maneira sutil, um breve panorama da "crise"; e (2) refletir sobre a insuficiência da educação moral contemporânea diante da natureza da crise identificada.

\section{Sobre a "crise" moral}

Conforme já dito logo na introdução deste artigo, não é possível catalogar a diversidade de trabalhos produzidos acerca da "crise" moral que nos assola, nem mesmo um recorte daqueles distribuídos nos diferentes âmbitos da Bioética. "Crise", talvez seja a palavra mais pronunciada nos tempos atuais. Com diferentes variações em seus qualificadores, apontam-se "crises" por toda parte. Em se tratando de um artigo de pretensão filosófica, caberia antes, de- 
finir a "pura" crise, aquela "cisão" da qual todas as demais crises são apenas predicados. Podemos começar pela seguinte postulação: trata-se de uma "entente tensa" entre a) uma percepção que se tem do que quer que seja; b) uma idealização que se tem do que quer que seja; e c) aquilo que, de fato, se dá, se manifesta, do que quer que seja. Em outras palavras, a "crise" seria a cisão e conflito entre percepção, idealização e o fato, imanente à existência. Vamos destrinchar o postulado, a partir de seus conceitos, para uma melhor aproximação.

Sobre a percepção, não é difícil compreender que tudo que "acontece" é, necessariamente, "presenciado" pelo humano. Existe uma antiga pergunta que diz: se uma árvore cai numa floresta, e não houver ninguém por perto, ela faz barulho? Se não houver um ouvido humano, certamente que não, pois barulho é uma concepção pertinente ao "ser"-humano. Mundo e homem são parceiros inseparáveis nesse "jogo" do ser. Se buscarmos a definição de "homem", no interior do pensamento grego, temos a seguinte expressão: zoon logon echon, traduzido e desfigurado, desde a latinização das noções filosóficas gregas, como "animal rationale". Heidegger (2008, p. 69) recorrentemente denunciava essa deformação de sentido provocado pela romanização da cultura grega:

A dominação dos romanos e sua transformação do helenismo no modo latino não se limita, entretanto, de nenhuma forma, a instituições individuais do mundo grego ou a atitudes individuais e "modos de expressão" da humanidade grega. Nem a latinização do mundo grego pelos romanos se estende, simplesmente, à soma de cada coisa apropriada por eles. O decisivo é que a latinização ocorre como uma transformação da essência da verdade e do ser no interior do domínio da história greco-romana. Essa transformação tem a característica de que ela permanece escondida e, entretanto, determina previamente tudo. Esta transformação da essência da verdade e do ser é o genuíno evento na história.

Ao resumir a expressão zoon logon echon à "animal racional", a metafísica Ocidental teria definido a experiência humana em sua dimensão "zoológica", esquecendo-se de sua essência verdadeiramente "ek-sistente". Em seu conjunto de ensaios reunidos sob o título Marcas do Caminho (2008, p. 336), Heidegger elabora melhor esta ideia quando diz que "a ek-sistência só pode ser dita da essência do homem, ou seja, apenas do modo humano de "ser"; pois, até onde podemos experimentar, só o homem é abandonado no interior do destino da ek-sistência". Inwood (2002, p. 58), em seu dicionário sobre Heidegger, nos ajuda a compreender o sentido que Heidegger propõe ao termo ek-sistência: "Heidegger frequentemente escreve Ex-sistenz ou Ek-sistenz para enfatizar o 'passo para fora"'. Logo, é a abertura "provocada" pelo homem que permite que as coisas "sejam" e, necessariamente, tenham sentido, valor. A desfiguração da expressão, além disso, teria esquecido o significado original de physis como o surgimento luminoso da "presença" (Dasein), contida na palavra zoon, bem como o significado primário do logos como o sentido como as coisas se apresentam no horizonte da experiência humana, completamente desvirtuado em sua tradução como ratio. (HAAR, 1993, p. xxiii)

A idealização, segundo elemento de nossa postulação preliminar sobre a questão da "crise", pode ser compreendida, por sua vez, como o desejo que se tem sobre o acontecido, e está intimamente relacionada com a percepção que temos de tudo que participamos, tudo que nos cerca, em última instância. Em seu ensaio O tempo da imagem no mundo, Heidegger (2014, p. 97) faz uma colocação de suma importância para nossa compreensão.

Na metafísica cumpre-se a meditação sobre a essência do ente e uma decisão sobre a essência da verdade. A metafísica funda uma era, na medida em que, através de uma determinada interpretação do ente e através de uma determinada concepção da verdade, Ihe dá o fundamento da sua figura essencial. Este fundamento domina por completo todos os fenômenos que distinguem essa era. Em sentido contrário, o fundamento metafísico tem 
de se deixar reconhecer nestes fenômenos, para uma meditação suficiente sobre eles. A meditação é a coragem para tornar no que é mais questionável [Fragwürdigste] a verdade dos pressupostos próprios e o espaço dos objectivos próprios.

O termo "metafísica", em Heidegger, deve ser compreendido como uma forma específica de interpretar o ente, de caracterizá-lo, compreendê-lo ${ }^{1}$. Essa interpretação se manifesta numa atitude prática e efetiva em relação às coisas, um modo de se situar diante delas, de se relacionar com tudo. Ou seja, idealizam-se ações e acontecimentos a partir dos referenciais interpretativos que compõem a "abertura" que somos. Quando pessoas que nos cercam são julgadas, sob a forma de uma condenação ou elogio, está implícito neste julgamento que se acredita nas noções de liberdade e livre-arbítrio, por exemplo. Afinal, atitudes não poderiam ser julgadas por um critério que não existe. Isso significa que, se acredito nas dualidades certo/errado, bom/mau, esta "crença" se manifesta no meu modo de interpretar os atos e fatos dos quais sou partícipe, ou seja, para qualquer decisão que vejo alguém tomar, imediatamente posso enquadrá-la nos "modelos" que pré-estabeleci.

Como se não bastasse a complexidade aí já posta nesse imbricado tecido de relações, temos ainda o terceiro elemento de nossa tríade. Trata-se do fato, o fenômeno "puro" e simples. A "coisa mesma", desprovida das percepções e das idealizações. O fato, "ele mesmo", é algo tão distante e complexo que Nietzsche, o filósofo do martelo, chegou a afirmar que não existe. Em seu clássico Genealogia da Moral, Nietzsche (2013, p. 263) radicaliza: “Contra o positivismo, que atesta ao fenômeno, 'só existem fatos', eu objetaria: não, justamente não há fatos, somente interpretações. Não podemos constatar nenhum factum 'em si': talvez seja um nonsense querer este tipo de coisa". Não nos arriscaremos nesta perigosa afirmação. De todo modo, entendemos que a própria história do pensamento é, na verdade, o processo de sedimentação das camadas e mais camadas de interpretação sobre como estes "acontecimentos" tomam lugar e como devem ser interpretados. Assim, tanto percepção como idealização se vêem desde sempre inteiramente comprometidas com estas infinitas camadas de pré-conceitos que, como óculos, contaminam o "aparecer" de qualquer coisa, do ente, do ser que se "dá". E aí, precisamente, está a "crise". Infinitas percepções, múltiplas idealizações, mas somente um fato, o fenômeno "ele mesmo". Neste sentido, a "crise" é o ponto culminante, radical de qualquer fenômeno, a entente "tensa" entre o que é percebido no interior da experiência humana, o que é desejado ou idealizado pelo homem e o que de fato "se dá" ou acaba por acontecer.

Podemos pensar um pouco, agora, sobre a crise "qualificada", ou seja, aquela que é objeto desta investigação, a saber: a crise ética. Trata-se de um choque entre (1) aquilo que percebo acontecer à minha volta, aí incluídas as decisões que presencio de outrens e etc; (2) o enquadramento deste acontecimento numa matriz clivada na dicotomia certo/errado (bom e mau); e (3) aquilo que, efetivamente, acontece, o que se "deu", enquanto fato. O imbróglio destas três instâncias, por assim dizer, caracteriza a natureza íntima da crise ética. A bem da verdade, "qual peixes que se movem sempre no mar, desde sempre nos encontramos nesta crise", diz Cabral (2009, p. 18). "É desde seu vigor que a totalidade dos nossos afazeres, isto é, a totalidade dos matizes da cultura cresce no seu movimento de realização", complementa o autor (ibidem). No fundo, todo o vigor da crise se assenta na concepção de que a razão é o instrumento pelo qual o homem é capaz não só

\footnotetext{
1 "[...] segundo Heidegger, a "metafísica" é um modo de determinar o ente, de interpretá-lo, de caracterizá-lo e de compreendê-lo. Não se trata, necessariamente, de uma espécie de visão intelectual, de uma concepção explicitamente formulada ou de um discurso sistemático sobre o ente. Sem dúvida, a compreensão do ente pode se exprimir num discurso. Mas ela é, antes de tudo implícita, vivida. A interpretação do ente é, primordialmente, uma atitude prática e efetiva em relação a ele, um modo de nos situarmos diante dele, de nos relacionarmos com ele. Portanto, no sentido heideggeriano, a metafísica é, primordialmente, uma determinação fundamental do ente que se constitui no implícito e que só é tematizada no discurso de modo secundário." (LADRIÈRE, 1994, p. 18).
} 
de de interpretar a totalidade do real como operar sobre ele. Neste sentido, acentua a "entente" mencionada na medida em que "impõe" ao homem a possibilidade de uma transformação do modo pelo qual o real se manifesta. Nossas "decisões", se tomadas desde uma razão "pura", são capazes de alterar o"ser" ou até mesmo corrigi-lo, como nos diz Nietzsche (1992, p. 93):

[...] junto a esse conhecimento isolado ergue-se por certo, com excesso de honradez, se não de petulância, uma profunda representação ilusória, que veio ao mundo pela primeira vez na pessoa de Sócrates - aquela inabalável fé de que o pensar, pelo fio condutor da causalidade, atinge até os abismos mais profundos do ser e que o pensar está em condições, não só de conhecê-lo, mas inclusive de corrigi-lo. Essa sublime ilusão metafísica é aditada como instinto à ciência, e a conduz sempre de novo a seus limites, onde ela tem de transmutar-se em arte, que é o objetivo propriamente visado por esse mecanismo.

Assim, na esteira da representação "racional" da realidade, as éticas modernas e, por conseguinte, grande parte da "educação moral" de nosso tempo, se encontram tomadas pela mesma fantasia de onipotência que corrói a interpretação científica da realidade. Nas palavras de Cabral (2009, p. 20-21), ao fundo desta concepção está a ideia de que "a razão é o 'carro-chefe' ou o 'coração' do ente que somos". Além disto, a razão é também o agente norteador ou "o elemento que irriga e vitaliza todo o desenvolvimento dos possíveis modos de ser do homem" (ibidem). Valores outrora instituídos caíram em desuso. Modelos e interpretações sobre o homem e a realidade, estruturadores e norteadores do agir humano, de um modo geral, foram inteiramente corroídos na Modernidade. Se a cultura grega nos legou - sobremaneira no entendimento de physis dos gregos homéricos - uma aquiescência na aceitação daquilo que "é", o período medieval é marcado pelos ditames da fé, afinal, "Deus sabe o que faz". Mas, e a Modernidade? A Modernidade marca o rompimento dessas estruturações. A razão surge, agora, como o norte de toda a existência humana. Cabral (2009, p. 21) utiliza o termo "raciocentrismo", que faz com que "tudo e todos devem aparecer sob o holofote da razão".

Ocidente é o lugar produzido pelo homem norteado pela força da racionalidade. Neste sentido, tomando emprestado a máxima de Hegel, deve-se reconhecer que o Ocidente é o lugar onde "todo real é racional". É desde a razão que o real aparece no Ocidente. Por isso, o Ocidente é o lugar onde a razão é o "carro-chefe" ou o "coração" do ente que somos, isto é, o lugar onde a razão é o agente norteador ou o elemento que irriga e vitaliza todo o desenvolvimento dos possíveis modos de ser do homem. Entendemos por raciocentrismo a singularidade do modo de ser do Ocidente, que posiciona a razão como norte de todo modo de ser do homem. O nascimento do raciocentrismo tem lugar e data marcados. Trata-se, segundo Nietzsche (2003b, p. 78-96) e Heidegger (1978, p. 27-29), do momento em que surge o pensamento de Sócrates ou Platão, na Grécia, no século V a.C. Desde então, tudo e todos devem aparecer sob o holofote ou brilho da razão. Por isso, é desde o referido século que a razão aparece como inquisidora e o real, como inquirido. Desde o momento em que tudo, para ser, tem de passar pelo crivo ou tribunal da razão, a máxima de Hegel todo real é racional - tornou-se credo ou dogma indiscutível na destinação do Ocidente. É aí que o sentido etimológico de razão aparece. Razão, raison, razón advêm, como se sabe, da palavra latina ratio, cujo significado é medida. Neste sentido, razão deve ser entendida como faculdade inerente ao ente humano capaz de representar o real sob conceitos ou inteligir sua essência (qüidittas). A razão, então, é a faculdade que mede o real, segundo o seu poder de ação. Ao medir o real, a razão passa a dizer o que o real é e os critérios necessários para que ele seja reconhecido como tal. Como conseqüência necessária, somente dentro do poder de ação da razão o real é real. O que não for mensurável ou captável pela razão nada é. Se outrora, antes do nascimento do raciocentrismo, o mythos servia como instrumento de interpretação do real, agora, para ter valor, tudo deve ser racional. Não mais se busca entender o real por meio da mitologia homérica, da cosmogonia e teogonia de Hesíodo, das palavras mágicas dos sacerdotes ou mesmo do poder sapiencial dos sábios, mas tãosomente a partir da razão ou lógos. Real passa a ser tão-somente o que for lógico. 
Esse delírio, no entanto, quando absorvido pela reflexão ética - e incluído na agenda educacional - acredita que a razão não só é capaz de "dizer" o real, mas diz também o que o real "deve" ser. Está estabelecida, agora, a grande chaga dos tempos modernos: a ideia do dever-ser.

A ideia do "dever ser" é, na cultura humana, a marca do desastre, a chaga aberta na Consciência pela inconsciência, o sintoma do desequilíbrio, da desarmonia e do conflito, o lugar hipersensível da dor e do sofrimento, a principal estrutura de sujeição, a rede obscurecedora da atenção, o sulco por onde nossas melhores energias são drenadas, o primeiro de todos os pontos de identificação, o resultado mesmo dessa condição humana, o ponto de vista. Trata-se, pois, do próprio inferno. O dever ser não é, mas, relativa ou absolutamente, "deveria" ser. Ele "não é" o que é. E "é" o que não é. Mas a estrutura dessa ilusão é tal, que, sem juízos de valor, não haveria fenômeno, não haveria um "mundo". Tratase de algo análogo à própria linguagem: o symbolon é o que está no lugar de outra coisa; é o que faz as vezes de outra coisa. Sob esse aspecto, é "o falso" por excelência. E outra vez: a estrutura dessa ilusão é tal, que, sem linguagem, não haveria um mundo. (FERNANDES, 1995, p. 25-26).

Aguilhoada por uma interpretação desfigurada de "homem", vimos de maneira incessante e com vigor cada vez maior, que ética e educação mergulham apressados em busca de uma salvação pelo "deus" razão. Toda e qualquer ruptura com "um certo modelo de racionalidade apresentou-se como abertura para uma nova forma de vigoramento da razão", diz Cabral (2009, p. 25). Desde a ruptura com os paradigmas greco-romanos pela racionalidade medieval, até o surgimento de Feuerbach e do marxismo, assistimos repetidamente o surgimento de um novo modelo de racionalidade, sobrepondo-se ao antigo, num círculo ininterrupto de "revigoramento" da racionalidade (ibidem), que encontra o seu vértice na Modernidade. Logo, a dita "crise moral" que tanto se menciona é, na verdade, uma crise do paradigma racional e, por conseguinte, da "subjetividade". Tal qual a "beleza", na estética moderna, está nos olhos de quem a vê, é no sujeito-racional, agente, que se encontra a moral, desde agora. Está devidamente imposta a preponderância do individualismo, do sujeito cartesiano, do sujeito do conhecimento, mas também do agir, do decidir egocêntrico. A bem da verdade, a crise da ética é, na verdade, uma crise da razão.

Em outras palavras, no abandono dos demais modos de interpretar o real, passamos a ter uma crise, ou melhor dizendo, sucessivas e múltiplas "crises" que vão assolar a Modernidade segundo qualificações aparentemente diferentes. Com o individualismo, desde o "nascimento do sujeito" com Descartes, mobiliza-se um novo sentido da crise, uma agudização do contraste que mencionamos. A própria ideologia de "progresso", no nascedouro da Modernidade, ou seja, da crença em uma "idade de ouro" futura e não mais "originária", acrescida de um entendimento da razão como capaz de resolver todos os obstáculos da experiência humana, de conter e controlar tanto a natureza externa como interna do homem, nos fazem ver o impacto do raciocentrismo que vivemos na Modernidade.

\section{Considerações sobre insuficiência da educação moral moderna}

Na seção anterior, estabelecemos alguns rudimentos importantes para a compreensão da crise e, em particular, a crise moral contemporânea. O"homem" moderno, doravante tratado, é o agente livre, regido por sua "afiada" razão. De acordo com Cabral (2009, p. 19), "ser livre, para este tipo de espírito, é livrar-se do "Tu deves". Não se diz mais: "sigo o que disseram que devo"; mas: "devo seguir justamente o que quero". O homem, ele próprio, é agora legislador e "plasmador" de todo o agir ético. Logo nas primeiras palavras de seu ensaio sobre $O$ que é o 
Esclarecimento?, de 1783, no auge da llustração, Kant (1974, p. 100) fundamenta, de uma vez por todas, os paradigmas da educação moderna ao anunciar:

Esclarecimento [Aufklärung] é a saída do homem de sua menoridade, da qual ele próprio é culpado. A menoridade é a incapacidade de fazer uso de seu entendimento sem a direção de outro indivíduo. $O$ homem é o próprio culpado dessa menoridade se a causa dela não se encontra na falta de entendimento, mas na falta de decisão e coragem de servir-se de si mesmo sem a direção de outrem. Sapere aude! Tem coragem de fazer uso de teu próprio entendimento, tal é o lema do esclarecimento [Aufklärung].

Para Charles Taylor (2011, p. 14), não há dúvida de que a sociedade ao se ver livre de uma estrutura sagrada já carcomida, ao colocar de lado as velhas ordens que regiam a existência humana, os arranjos sociais e os modos de ação não se encontram mais fundamentados em qualquer ordem das coisas ou muito menos em uma vontade divina, e assim passem a estar disponíveis: "podem ser redefinidos tendo suas consequências voltadas para a felicidade e o bem-estar dos indivíduos como nossa meta" (ibidem). Doravante o único critério que se aplica é o da "razão instrumental" de um sujeito-agente. Perdemos radicalmente a dimensão heróica da vida, escreve Taylor, exatamente porque não somos mais capazes de encontrar um propósito maior pelo qual "vale a pena morrer" (idem, p. 13).

Essa instrumentação do homem moderno, que Heidegger (2002, p. 18-38) acentua por várias declinações do verbo stellen (pôr) constitui o viger da essência da técnica moderna (Gestell ${ }^{2}$ ) diante de tudo. Isso se aplica também para as criaturas que nos cercam, que perdem o significado que lhes foi atribuído de acordo com seu lugar na cadeia de entes e, neste sentido, podem ser tratadas como objeto, matéria-prima ou instrumentos para nossos projetos. Essa dimensão essencial de com-posição (Ge-stell) da técnica com o mundo vige, desde então, de modo cada vez mais radical, seja na interpretação da realidade ou ainda na reflexão ética. Neste sentido, o domínio planetário da técnica avança, também, sobre a reflexão ética moderna e educação moral, que se apropriam de um "pensar" já obnubilado pelo cálculo. Para Heidegger (2008, p. 330), quando cessa o pensar, se afastando de seu horizonte de atuação, ele tende a se

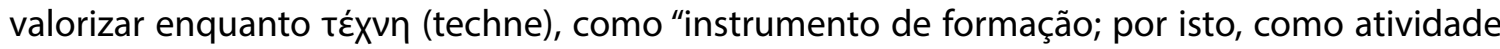
acadêmica e, posteriormente, como empreendimento cultural" (ibidem).

Se quisermos uma vez aprender a experimentar de maneira límpida a citada essência do pensar, o que significa igualmente levá-la a cabo, devemos nos livrar da interpretação técnica do pensar. Os começos dessa interpretação remontam até Platão e Aristóteles. 0 próprio pensar equivale aí a uma téxvn [techne], o proceder da reflexão a serviço do fazer e do operar. [...] Desde então, a "filosofia" se vê constantemente constrangida a justificar sua existência diante das "ciências". Ela imagina que isto aconteça do modo mais seguro, quando ela eleva a si mesma ao patamar de uma ciência. Esse esforço, porém, é a renúncia da essência do pensar. A filosofia é perseguida pelo medo de perder prestígio e importância, caso não seja uma ciência. (HEIDEGGER, 2008, p. 327).

Nessa mesma toada, o caráter mais saliente da moral moderna e sua pretensa "educação", é que se considera independente de qualquer autoridade que não seja o sujeito-agente ${ }^{3}$, apenas afeito ao pensar calculativo de natureza científico, que em tudo afirma e consagra o paradigma sujeito-objeto. Com o pensamento de Descartes e, pouco depois que a reforma protestante proclamara o livre exame e a autonomia absoluta em matéria religiosa, num tempo que os ataques

\footnotetext{
2 "Chamamos aqui de com-posição (Ge-stell) o apelo de exploração que reúne o homem a dis-por do que se des-encobre como disponibilidade" (HEIDEGGER, 2002, p. 23).

${ }^{3}$ O império da "'subjetivação': isto é, o centro das coisas cada vez mais no sujeito, e de várias maneiras. Coisas que foram um dia estabelecidas por alguma realidade externa - a lei tradicional, digamos, ou a natureza - agora são referidas como nossa escolha. Questões em que devíamos aceitar os ditados da autoridade, agora precisamos pensar por nós mesmos. (TAYLOR, 2011, p. 84).
} 
da Renascença já haviam desprestigiado as teorias tradicionais, a educação moral moderna rompe definitivamente com o passado e seus principais representantes se esforçam para constituir alicerces inteiramente novos, dignos dos "novos tempos". O pensamento secularizado se afasta, por vezes até de maneira hostil, dos paradigmas da Idade Média e se apropria de uma filosofia grega inteiramente romanizada, e desfigurada, conforme já dissemos.

Hoje, ainda sob o vigor do projeto da llustração (Aufklärung), cabe "educar" o homem-racional para que seja "mestre e senhor"4 tanto da natureza que o cerca, como daquela que tem dentro de si. A moralidade se encontra agora, inteiramente à mercê da razão. Em sua obra Dialética do Esclarecimento, Adorno e Horkheimer (1985, p. 19), devidamente cientes das atrocidades cometidas na Segunda Grande Guerra, escreveram: "no sentido mais amplo do progresso do pensamento, o esclarecimento tem perseguido sempre o objetivo de livrar os homens do medo e de investi-los na posição de senhores. Mas a terra totalmente esclarecida resplandece sob o signo de uma calamidade triunfal". Tornou-se evidente que, a existência humana, quando regida pelo poder da razão, elevada à sua potência máxima, corre o risco de ser conduzida por uma "lógica pura", ou logística como denominou Heidegger (2005, p. 15-16), aplicada equivocada e maquinalmente. Portanto, uma existência incapaz de se colocar à escuta de algo "mais", resultando em argumentos absurdos como as justificativas que se davam para um holocausto medonho ou experimentos científicos descabidos. Vamos ler esta longa, mas importante, passagem de Cabral (2009, p. 25):

Não mais se acredita no "deus razão"; suas promessas já estão desacreditadas no Ocidente. Como um ícone ou ídolo religioso nas mãos de um iconoclasta, o fideísmo ou crença desenfreada na razão foi quebrado e, concomitantemente, quebrou-se também a crença nas éticas até então vigentes. É por isso que, hoje, multiplicam-se livros, artigos, revistas e encontros que versam exclusivamente sobre ética e, às vezes, sobre propostas de reformulação ou mesmo criação de um novo paradigma ético. Por isso, ouvimos falar dos mais variados tipos de ética - ética da libertação, ética da vida, ética dialógica, ética da alteridade etc. - e vemos, além disso, o surgimento de uma pluralidade de movimentos que tentam viabilizar a implementação de suportes éticos nos mais variados setores da cultura ética na política, ética na educação, ética nas empresas, ética na ciência etc. Aparentemente, a pulverização destes movimentos indica a contradição da nossa afirmação inicial, a de que a ética entrou em falência por causa da crise da racionalidade como motor do Ocidente, porque todas estas éticas ou movimentos de implantação da ética nos mais diversos setores da cultura vigem a partir da razão, do lógos. Mas isto é, de fato, somente aparência. Tais movimentos mostram justamente a escassez de uma racionalidade homogênea no Ocidente. A luta desenfreada pela busca de um revigoramento da racionalidade como fonte de todo e qualquer pensamento ético, hoje, não é sintoma do imperialismo da razão, mas de sua decadência. Se estamos em busca de um novo pensamento ético, é porque já saímos daquele horizonte racional desde o qual ele emerge. [...].

Entendemos, portanto, que o grande fracasso do pensamento moral, que hoje temos em voga, bem como seus desdobramentos na educação, se assenta no fato de que procura, incessantemente, um padrão objetivo e racional que possa operar de modo decisivo na ética, da mesma maneira como fez no domínio da matemática, da lógica ou da ciência. Como uma quimera, o pensamento moral se afoga em um mar de representações delirantes, que clamam encontrar uma "medida certa" para todos os conflitos. A pretensa "educação moral", assentada numa concepção empobrecida da experiência humana como "sujeito racional", não encontra outra saída senão produzir um número infindável de regras, cartilhas, diretrizes e normas para o agir humano. Não se trata de dizer que a educação moral contemporânea, calcada nas teo-

\footnotetext{
${ }^{4}$ Expressão consagrada por René Descartes em seu clássico Discurso sobre o método (2006, p. 51).
} 
rias morais tradicionais, sejam falsas ou ainda, dispensáveis. Mas não são capazes de des-velar (aletheia) a dimensão de profundidade mas apenas a largura e o comprimento, o plano horizontal de amplitude e de complexidade da superfície da praxis. A interpretação de Heidegger sobre alegoria de Platão, no livro VII da República é ilustrativa. Em sua obra Marcas do Caminho, Heidegger (2008, p. 230) fala sobre a força interpretativa da história. Para Heidegger, Platão deseja tornar visível e cognoscível a essência da paideia, a formação do homem grego, na plasticidade da história narrada (ibidem). Em forma de rechaço, Platão quer mostrar também que a paideia não tem a sua essência "em entulhar a alma despreparada com meros conhecimentos, como se faz com um recipiente vazio, que se apresenta arbitrariamente", diz Heidegger (ibidem). Muito ao contrário, a verdadeira paideia apanha e transforma o homem na sua totalidade, alocando-o antes de tudo em seu lugar essencial, numa outra dis-posição frente as situções de que participa. Essa é necessária paideia que deve embasar qualquer educação moral. Segundo Danielle Montet (1990, p. 187-188), um termo grego cujo campo semântico de "educação" ou "formação" não apreende embora articulada ao redor do termo grego pais, infante. Pois enquanto as línguas latinas qualificam o infante a partir de seu mutismo (infans), "o grego sublinha no pais uma incompletude que excede a falta da linguagem". Essa mesma incompletude que vai caracterizar "ser"-humano em sua permanente finitude como humano sempre carente de paideia.

\section{Considerações finais}

O percurso, dentro dos limites de um artigo, foi iniciado por considerações sobre a exigência de um pensar meditativo desde o interior da metaética, capaz de efetivamente fundamentar a Bioética. Em seguida, pontuou-se o sentido de "crise" de modo a estabelecer o horizonte necessário para se pensar a crise moral que se estrutura, no final das contas, devido à acelerada tecnicização da ética, ou seja, devido à inssurgência da essência da técnica (Ge-stell, com-posição) fora de seus domínios, em franca incursão na consumação dos atos-fatos da Saúde. Por fim, foi possível alinhar algumas reflexões sobre a possibilidade da Bioética arquitetar uma educação moral, desde que centrada em uma paideia que lide com a permanente finitude do humano em "ser"-humano.

É sempre tarefa árdua esta que toda "conclusão" nos coloca. Trata-se de dar um "fim", no sentido de término e de finalidade, ao pensamento filosófico. Isto significa retirá-lo de seu lugar essencial, onde vagueia, incontrolável, inútil, reunindo considerações sobre o tema, jamais em linha reta, mas em um círculo que em muitos casos é interpretado como "sem sentido", dada sua natureza aporética, e sem "utilidade". Heidegger (2011, p. 241) diz que o movimento circular próprio à filosofia não encontra o seu elemento essencial no fato de andar ao longo de uma periferia, de onde pouco se vê. Ao contrário, diz Heidegger (ibid.): o olhar para o centro, "só é possível no curso circular". Fato é que, há muito, nos afastamos do "pensamento essencial". Desfigurado de seu fundamento "inútil", o pensamento busca se colocar à altura do nosso tempo quando produz um determinado resultado, uma "conclusão", que seja capaz de trazer certo sossego, alguma justificativa e sobretudo validade diante das "ciências". Mas assim sendo corre o risco de se qualificar como "pensamento calculativo".

Isto posto, para além de um "fechamento", tão comum a uma "conclusão", propomos que estas linhas finais, bem como todo o diagnóstico proposto neste artigo, sirvam como um apelo à uma nova abordagem para o que se consagrou pela expressão "educação moral", nos dias de hoje. O conjunto de palavras aqui reunidas devem servir como apontamentos para a necessi- 
dade de uma verdadeira paideia que se situe além da ditadura da razão, isto é, de um "sistema universal de prestar contas e dar explicações evidentes e suficientes, coerentes e consistentes de tudo que é, de tudo que se conhece e de tudo que se faz, seja nas ações que se põem, seja nas atitudes que se tomam, seja nas omissões, que se praticam", conforme bem explicita Carneiro Leão (2010, p. 132). Entendemos até que, o que foi aqui dito, pode ser interpretado no sentido de uma therapeia, ou melhor, um logos terapêutico, que no exercício de um pensar "inútil", ou seja, de um movimento circular próprio à filosofia, seja capaz de amplificar o apelo do ser, o grito silencioso que nos convoca, uma vez mais, a colocar a reflexão sobre a ética, e a educação ética, em um novo horizonte de pensar o "ser"-humano.

\section{Referências}

AGAMBEN, Georgio. "God didn't die, he was transformed into money". An Interview with Giorgio Agamben - Peppe Savà. 2012/2014. Disponível em: https://libcom.org/library/god-didnt-die -he-was-transformed-money-interview-giorgio-agamben-peppe-sav\%C3\%A0

CABRAL, Alexandre. M. Heidegger e a destruição da ética. Rio de Janeiro: Editora UFRJ, 2009.

CARNEIRO LEÃO, Emmanuel. Filosofia Grega: uma introdução. Teresópolis: Daimon Editora, 2010. DESCARTES, René. A Discourse on the Method of Correctly Conducting One's Reason and Seeking Truth in the Sciences. Tradução de lan Maclean. Oxford: Oxford University Press, 2006.

HAAR, Michel. Heidegger and the essence of man. Tradução de William McNeill. Albany: State University of New York Press, 1993.

HEIDEGGER, Martin. Hölderlin's Hymn "The Ister". Tradução de William McNeill e Julia Davis. Bloomington: Indiana University Press, 1996.

HEIDEGGER, Martin. Ensaios e conferências. Tradução de Emmanuel Carneiro Leão, Gilvan Fogel e Marcia Schuback. Petrópolis: Vozes, 2002.

HEIDEGGER, Martin. “Que significa pensar?". In: SCHNEIDER, Paulo Rudi. O outro pensar. Sobre "Que significa pensar? e "A época da imagem do mundo" de Heidegger. ljuí: Editora Unijuí, 2005.

HEIDEGGER, Martin. Marcas do caminho. Tradução de Enio Paulo Giachini e Ernildo Stein. Petrópolis: Vozes, 2008.

HEIDEGGER, Martin. Caminhos de floresta. Tradução de Irene Borges-Duarte. Lisboa: Fundação Calouste Gulbenkian, 2014.

HORKHEIMER, Max; ADORNO, Theodor. W. O conceito de esclarecimento. In: HORKHEIMER, M.; ADORNO, T.W. (Orgs.). Dialética do esclarecimento: fragmentos filosóficos. Tradução de G. A. Almeida. Rio de Janeiro: Zahar Editor, 1985.

INWOOD, Michael. Dicionário Heidegger. Rio de Janeiro: Zahar Editor, 2002.

KANT, Immanuel. Immanuel Kant: textos seletos. Petrópolis: Editora Vozes, 1974. LADRIÈRE, Jean. Del sentido de la Bioética. Acta bioeth. Santiago, v. 6, n. 2, p. 197-218, dic. 2000. Disponível em: https://scielo.conicyt.cl/scielo.php?script=sci_arttext\&pid=S1726-569X 200000 0200002\&lng=es\&nrm=iso. Acesso em: 22 mar. 2019.

LADRIÈRE, Jean. Ética e pensamento científico: a abordagem filosófica do problema bioético. São Paulo: Editora Letras \& Letras, 1994.

MITRE, Sandra Minardi et al. Metodologias ativas de ensino-aprendizagem na formação profissional em saúde: debates atuais. Ciênc. Saúde Coletiva, Rio de Janeiro, v. 13, supl. 2, p. 2133-2144, 
dez., 2008.Disponívelem:http://www.scielo.br/scielo.php?script=sci_arttext\&pid=S1413-81232 008000900018\&lng=en\&nrm=iso. Acesso em: 22 mar. 2019.

MONTET, Danielle. Les traits de l'être. Grenoble: Jerôme Millon, 1990.

MOTTA, Luís Claudio de Souza. O cuidado no espaço-tempo do Oikos: sobre a bioética e a estratégia de saúde da família. 2012. Dissertação. (Mestrado em Bioética, Ética Aplicada e Saúde Coletiva). Instituto de Saúde Coletiva da Universidade Federal do Rio de Janeiro (IESC-UFRJ), Rio de Janeiro, 2012.

NIETZSCHE, Friedrich. O nascimento da tragédia. São Paulo: Companhia das Letras, 1992.

NIETZSCHE, Friedrich. Ecce homo. Tradução de Pietro Nassetti. São Paulo: Editora Martin Claret, 2004. NIETZSCHE, Friedrich. Fragmentos póstumos (1885-1887) v. VI. Rio de Janeiro: Forense Universitária, 2013.

REGO, Sergio; COSTA-MACEDO, Leda M. Subsídios para a educação moral nos cursos de graduação em saúde. In: SCHRAMM, F.R.; REGO, S.; BRAZ, M.; PALACIOS, M.(Orgs.). Bioética riscos e proteção. Rio de Janeiro: UFRJ/Fiocruz; 2005.

REGO, Sergio; GOMES, Andréia Patrícia; SIQUEIRA-BATISTA, Rodrigo. Bioética e humanização como temas transversais na formação médica. Rev. Bras. Educ. Med. Rio de Janeiro, v. 32, n. 4, p. 482-491, dez. 2008. Disponível em: http://www.scielo.br/scielo.php?script=sci_arttext\&pid= S0100-55022008000400011\&lng=en\&nrm=iso. Acesso em: 24 mar. 2019.

TAYLOR, Charles. A ética da autenticidade. São Paulo: É Realizações, 2011.

VIDAL, Selma Vaz. Bioética, educação e estratégia saúde da família: entre práxis e paidéia. Tese (Doutorado em Bioética, Ética Aplicada e Saúde Coletiva). Instituto de Saúde Coletiva da Universidade Federal do Rio de Janeiro (IESC-UFRJ). Rio de Janeiro, 2014.

ZOBOLI, Elma Lourdes Campos Pavone; FORTES, Paulo Antonio de Carvalho. Bioética e atenção básica: um perfil dos problemas éticos vividos por enfermeiros e médicos do Programa de Saúde da Família, São Paulo, Brasil. Cadernos de Saúde Pública. Rio de Janeiro, v. 20, n. 6, p. 16901699, 2004.

\section{Sobre os autores}

\section{João Cardoso de Castro}

Doutor em Bioética pelo Programa de Pós-Graduação em Bioética, Ética Aplicada e Saúde Coletiva - UFRJ, com período sanduíche [CAPES] na DePaul University (Chicago). Possui graduação em Filosofia pela Universidade do Estado do Rio de Janeiro (2005) e mestrado em Educação em Ciências e Saúde pela UFRJ (2009). Atualmente é professor de Filosofia e Bioética em cursos de graduação e Coordenador da Editora da UNIFESO. Principais temas de atuação: filosofia antiga, Heidegger, fenomenologia, epistemologia, ética, Bioética.

Murilo Cardoso de Castro

Doutor em Filosofia (UFRJ), doutor em Geografia (UFRJ), com período sanduíche na Université Sorbonne Nouvelle Paris 3 (1999), mestrado em Geografia (UFRJ). Professor da UFRJ. 